\title{
In the Footsteps of the Gods: Janus Revisited and the Pursuit of Timeliness
}

\author{
Suzanne F. Bradley, MD
}

Janus, the Roman god of new beginnings and good endings, has been an important symbol and recurring theme since the inception of this journal. ${ }^{1-3}$ In 1980, Drs. Richard P. Wenzel and William A. Schaffner "introduced a new scientific journal that would focus on hospital epidemiology and all aspects of infection control.", In less than a decade, Infection Control evolved to become the official journal of the Society for Hospital Epidemiology of America (SHEA), renamed Infection Control and Hospital Epidemiology (ICHE). ${ }^{4}$

In 1993, Dr. Michael D. Decker assumed the helm. Dr. Decker vigorously pursued his goals to make ICHE the premier journal in hospital epidemiology, to make it the most cited in its field, and to increase its scientific content and the proportion of papers dedicated to original research..$^{5-7} \mathrm{By}$ 2000 , he had enhanced "the visibility and prestige of the Journal" so "that it would be able to compete with specialty and second-tier journals." By the close of his tenure in 2002, almost all submissions were original articles, and Dr. Decker had increased the global appeal of the journal, with almost $50 \%$ of submissions coming from outside North America. ${ }^{?}$

In 2002, Dr. Barry M. Farr became Editor-in-Chief of $I C H E$. Dr. Farr pledged to "maintain the scientific quality and global reach and content of the Journal, while trying to expedite both reviews and publication." ${ }^{8}$ ICHE entered the electronic publication age with the availability of a CD-ROM containing journal issues from the first decade and a Web site with on-line search capacity in 2003. The number of manuscripts submitted increased markedly during this time, and backlogs became a new issue for this young journal. Through sheer force of will and great personal effort, Dr. Farr and his editors did what they could to reduce the backlog at the level of the editorial office. Dr. Farr was a major force in searching for ways to expedite the review and publication process. He was and remains a tireless advocate for control of multidrug-resistant nosocomial infections. ${ }^{9}$ With his retirement from the University of Virginia, Dr. Farr was unable to continue as Editor of ICHE.

In July 2004, then Deputy Editor Dr. William R. Jarvis assumed the duties of Editor-in-Chief; he was officially appointed in January 2005. One of Dr. Jarvis's major challenges and achievements was presiding over the change of publishers from Slack Incorporated to the University of Chicago Press (UCP). ${ }^{10}$ With his leadership and UCP's vast experience in publishing such journals as Clinical Infectious Diseases and the Journal of Infectious Diseases, the visibility of ICHE has increased markedly. Manuscript submissions continued to increase, with further increase in the backlog. Dr. Jarvis sought to rectify the situation by increasing the number of pages per issue and increasing rejection rates. $\mathrm{He}$ also ensured that the increased rejection rate would not disproportionately impact submissions from international authors. During the transition to my editorship, Dr. Jarvis has been most gracious with his advice and his oversight of the assembly of early 2007 issues.

Now, the ICHE editorial office has moved to Ann Arbor, Michigan. In preparing for this editorial, I retrieved a version of Edith Hamilton's mythology text, a 38-year-old, tattered relic of a freshman high school English class. ${ }^{11}$ Written inside the front cover was a familiar but too legible scrawl with a definition for "hubris." This citation did not refer to the more common usage meaning "arrogance or conceit," but rather to "mere mortals aspiring to do the work of the gods." How does one follow in the footsteps of editors who are legends in infection control and the field of healthcare epidemiology? This is truly a task worthy of Hercules, or more likely, Sisyphus.

The temple of Janus had two doors; at each end stood his likeness, a statue with two faces. One side of his face depicted the god's likeness as a young man and the other as an old man. It would therefore seem appropriate that the transition of editorship be passed from Dr. Jarvis, a pediatrician, to me, a geriatrician. Dr. Jarvis' tireless efforts have led to a seamless transition and he has left the journal in excellent health. The continued growth of the journal under his tenure has left us with a plethora of accepted articles to be published.

The transition also could not have occurred as seamlessly as it did without the generous support of the SHEA Board

Dr. Bradley is the Editor of Infection Control and Hospital Epidemiology, and is from the Divisions of Infectious Diseases and Geriatric Medicine, Veterans Affairs Ann Arbor Healthcare System and the University of Michigan Medical School, Ann Arbor, Michigan.

Infect Control Hosp Epidemiol 2007; 28:373-374

(C) 2007 by The Society for Healthcare Epidemiology of America. All rights reserved. 0899-823X/2007/2804-0001\$15.00. DOI: 10.1086/515709 
of Directors and the professionalism, expertise, and patience of the ICHE office at UCP. Deputy Editor Dr. Carol Kauffman brings extensive editing experience to the editorial office at Ann Arbor. Associate Editor Dr. Preeti Malani has a unique background in journalism and editing that has been invaluable. In the past 8 weeks, both have worked very hard to rapidly make decisions on the majority of 69 outstanding articles from 2006 and have helped to process more than 70 new manuscripts from 2007. Candidates for two additional Associate Editors based outside of Michigan and a part-time statistician have been identified and should be in place shortly.

So, what can you expect as an author, reviewer, and reader of ICHE? The field of infection control and healthcare epidemiology requires rapid detection of infection, interpretation of data, and implementation of procedures to control the problem. New problems and emerging infections confront us that were not issues 27 years ago; creative solutions are required.

Original scientific investigations that seek to define problems and solutions are the lifeblood that moves this discipline forward. To serve the SHEA membership, these articles must continue to be the priority for publication in the journal. This journal needs to be at the forefront of publication about new outbreaks and important infection control topics. For this reason, rapid publication of timely original articles and equally well-done, but more focused, concise communications must be the first priority for the journal. Mechanisms to identify important articles for early publication in print or perhaps electronically are being developed. Thematic issues have delayed publication of articles that do not fit into a particular niche. I will suspend this practice at least until the backlog is under control. Editorials that provide an overview of the entire issue will be phased out in favor of commentaries pro and con regarding specific papers. As a god with 2 faces, Janus might support the concept of seeing both sides of an issue. More membership input on important topics, in the form of letters to the editor, will be encouraged.

Rapid publication of SHEA committee and task force guidelines and position papers is also a major priority. This will ensure dissemination to the membership of Society business and important new information in the field. Editorial special sections have been retired. In the electronic age, society news can best be disseminated by the SHEA Web site. It is my conviction that many of the activities served by Sections have been subsumed into the SHEA Special Interest Groups and Task Forces.

To decrease time to publication, especially in face of a backlog, several approaches are necessary. Many of these approaches are not novel. Dr. Jarvis pointed out that while rates of submission have continued to increase, rejection rates have remained relatively stable. ${ }^{10}$ We clearly cannot continue to do business as usual. To rapidly publish timely and important papers, more papers will need to be rejected and in a shorter period of time. Review of papers that are not likely to be published or do not add to the literature add work for reviewers, editors, and the publisher and delays papers that do need to be published. Rapid rejection allows authors to revise and submit elsewhere. Reduction in number of manuscripts for review should reduce reviewer fatigue.

Increasing the number of qualified reviewers to support their Society's journal continues to be a problem. Five years ago, Dr. Farr pointedly identified this very issue. "...I was shown a computer file that shocked me. The file showed how frequently SHEA members had been asked to review manuscripts for ICHE and how frequently they refused." $\mathrm{Dr}$. Jarvis had similar sentiments: "The longest delay in processing our submitted articles is incurred while we identify qualified reviewers with the time to review the paper." ${ }^{" 10}$ I can tell you that this situation has not changed appreciably. Many active and visible members of SHEA present papers at meetings and publish regularly in this journal but predictably and frequently refuse to review.

Increasing the quality and reducing the number of articles sent out for review will help. We do have a fairly small membership to draw upon. For those who have been faithful reviewers in the past, increasing obligations and reviewer fatigue may be an issue. I plan to restructure the Editorial Advisory Board so that members serve 3-year rotations. Excellent reviewers who have not served on the Editorial Advisory Board will be rewarded with an invitation to join.

Janus had the ability to look to the past and towards the future. Dr. Jarvis described ICHE as "transitioning through adolescence. ${ }^{10}$ I certainly hope that with a top-notch editorial team and publisher, enthusiasm, effort, and some changes in process, we can move the journal to early adulthood.

\section{REFERENCES}

1. Wenzel RP, Schaffner WA. Of Roman gods and a new journal. Infect Control 1980; 1:13.

2. Wenzel RP. Our journal-a new era. Infect Control Hosp Epidemiol 1993; 14:12-13.

3. Wenzel RP, Schaffner WA. A new affiliation, a new name, and a new direction. Infect Control Hosp Epidemiol 1988; 9:7.

4. Burke JB, Craven DE. An interregnum not! Infect Control Hosp Epidemiol $1993 ; 14: 11$.

5. Decker MD. Change and constancy. Infect Control Hosp Epidemiol 1993; 14:14.

6. Decker MD. Help wanted. Infect Control Hosp Epidemiol 2000;21:757-759.

7. Decker MD. Change and constancy, 2002. Infect Control Hosp Epidemiol 2002; 23:10.

8. Farr BM. Change, constancy, and help wanted (from the whole village). Infect Control Hosp Epidemiol 2002; 23:11-12.

9. Farr BM. Volume 25: an important milestone despite continuing infection control challenges. Infect Control Hosp Epidemiol 2004; 25:7-9.

10. Jarvis WR. Infection Control and Hospital Epidemiology: transitioning through adolescence! Infect Control Hosp Epidemiol 2006; 27:1-2.

11. Hamilton E. Mythology: Timeless Tales of Gods and Heroes. 40th ed. Mentor Books: New York; 1942. 